\title{
Study of the Impact of Collaboration among Teachers in a Collaborative Authoring System
}

\author{
Yacine Lafifi and Ghassen Touil \\ Computer Science Department, University of Guelma, \\ Guelma, Algeria
}

\section{Lafyac@yahoo.fr; touil_ghassen@yahoo.co.uk \\ Executive Summary}

Several researchers have studied the impact of collaboration between the learners on their cognitive levels, but few studies have been carried out on the impact of collaboration between the teachers. The aim of our research is to study the effects on the knowledge levels of learners of collaborative construction of learning objects created by the teachers. More precisely, the objective is to conceive a distance learning environment that takes into account many concepts and strategies. Among the tasks assigned to our research team is to study the effects of collaboration among learners on the one side and among teachers in the other side. In previous work, we have studied the impact of collaborative learning on the cognitive profile of learners. In this work, we focused on the impact of collaboration among teachers on both teachers and learners. The aim of this paper is to present a collaborative authoring system called SAC (which is the French acronym of Système Auteur Collaboratif). This is designed to be used in an academic environment. Moreover, it can be used by any academic institution adopting the LMD (Licence-MasterDoctorate) regime. Its principal feature is that it takes into account collaboration among teachers for construction of learning objects. In this case, teachers collaborate to build common products. They discuss and coordinate their efforts to build pedagogical content that reflects all their points of view. Through this system, the teachers can put their courses online in various formats (lessons, tutorials, presentations, etc.) and students can download lessons, self-assess, and communicate with their colleagues.

We used a certain number of criteria for making the collaboration task more efficient. These criteria are used by a search tool of co-authors, which is a part of SAC system. Among these criteria are the behavioral profile and the expertise area of teachers. The co-author search tool is like a search engine but it is used for searching authors in order to perform collaborative tasks.

The use of this system overcomes the difficulties met by teachers in traditional systems. These difficulties are mainly related to the lack of tools, and assistance means facilitating their tasks during the preparation of their learning objects. In fact, this system has many features for the organization of learning objects and the facilitation of the courses preparation. These courses are

Material published as part of this publication, either on-line or in print, is copyrighted by the Informing Science Institute. Permission to make digital or paper copy of part or all of these works for personal or classroom use is granted without fee provided that the copies are not made or distributed for profit or commercial advantage AND that copies 1) bear this notice in full and 2) give the full citation on the first page. It is permissible to abstract these works so long as credit is given. To copy in all other cases or to republish or to post on a server or to redistribute to lists requires specific permission and payment of a fee. Contact Publisher@InformingScience.org to request redistribution permission. those of the Licence degree.

SAC was implemented and tested by a sample of university students and teachers. The aim was to know the attitude of these actors toward the system and the content of the courses that are built collaboratively. The obtained results showed that the teachers enjoyed using the system. They were very satisfied with the main components of SAC, such 
Impact of Collaboration among Teachers

as the shared editor tool, the co-author search engine, and the trace manager. Particular attention was given to the co-authors search engine, which constitutes the main contribution of this paper. It was used by most of the teachers. This fact revealed its usefulness.

After rigorous analysis of the results, we observed that the collaboration among teachers has good effects on the cognitive profile of learners. All the details concerning the experiment as well as the obtained results will be presented and discussed at the end of this paper. Furthermore, we will present the problems faced by the participants (i.e., teachers and students) and a short description of the future work.

Keywords: Authoring System, Collaboration, Shared text editor, Pedagogical Objective, Coauthor search.

\section{Introduction}

Although the obstacles and problems in building distance-learning environments were and are still apparent, distance education is here to stay (Synnes, Parnes, Widen \& Schefstroem, 1999). Many universities offer course modules, whole courses, or even degrees online. Moreover, many companies offer various types of education-oriented material and pedagogical software using the Internet. Generally speaking, pedagogical courseware can be designed from scratch, in an application-oriented way, or built with general purpose authoring tools. Here, one of the new roles of teachers as courseware authors becomes clear (Cristea \& Okamoto, 2001). Nowadays, teachers either have to build their own, choose off-the-shelf Web courses (Kaplan, 1998) or choose among the various online course delivery tools, such as WebCT (http://www.Webct.com), Ganesha (http://81.252.101.17/ganesha/intro/index.php), or Claroline (http://www.claroline.net). Many universities have decided to build their own authoring tools for their faculty staff (Collis, 1999).

In traditional learning systems, teachers find difficulties in preparing their teaching content (i.e., subjects). These difficulties are mainly related to the lack of tools facilitating their tasks and assistance during the preparation of their subjects. Teachers can use the knowledge of their teammates. In fact, teachers can collaborate to design material for teaching a subject or any other pedagogical resource (presentation, demonstration, practical work, etc.). Collaboration may range from asynchronous, where an interactive activity is separated by long periods of time (e.g., e-mail, discussion groups), to synchronous, where an interactive activity is simultaneous (e.g., video conferencing). Synchronous collaborative systems are not as common as asynchronous systems. One of the most widely used synchronous collaborative technologies is telephony, where two or more people can remotely talk to each other in real-time. Computer based synchronous collaborative systems, like shared whiteboards, collaborative editor, etc., are only beginning to emerge recently (Zafer, 2001).

Several researchers showed the efficiency of collaborative learning on the cognitive and behavioral profiles of learners (Labidi, Lima \& Sousa, 2000; Lonchamp, 2006; Roberts, 2005; Serce \& Yildrim, 2006; Smith, 2005; Soh, Khandaker, Liu \& Jiang, 2006). In our previous work (Lafifi, 2007), we studied the effects of collaboration between learners on their cognitive levels. We found that such collaboration is efficient under some conditions. But, what is the impact of collaboration between other actors and, in particular, teachers? What are the tools dedicated to facilitate the collaboration process? How will the content of learning objects be delivered to learners? How can we determine the impact of this collaboration on the different levels of learners and even teachers?

In order to answer all these questions, we proposed to implement a collaborative authoring system called SAC (Système Auteur Collaboratif) (Lafifi, 2008). It is a part of a global research project aiming at conceiving a collaborative teaching system for the higher education institutions of Algeria. The task assigned to our team is to conceive a collaborative authoring/learning environ- 
ment (synchronous or asynchronous) by taking into account, other than the collaboration between the learners, the collaboration between the teachers for the preparation of the learning objects. In that case, teachers try to construct a common product by discussing and coordinating their efforts to build pedagogical contents that reflect all their points of view.

For this work to be widely used by the university community, the majority of whom do not possess programming skills, it has to accomplish two requirements: it must be widely independent from any study domain. and it must be easy to use by teachers rather than by learners. Furthermore, the teachers must be exempted from any programming activity.

The goal of this paper is to present the collaborative authoring system (SAC), which was implemented and experimented with university students and teachers. The rest of the paper is organized as follows. In the next section, we present an outline about the state-of-the-art synopsis concerning authoring systems and collaborative editing. The features of the realized system are presented in the next section. In addition, we will illustrate some screen-shots of SAC. In the next section, we show the first obtained results as well as the problems faced during the experiment. At the end, we give a conclusion and some perspectives on the potential for this system.

\section{Literature Review}

\section{Authoring Systems Background}

Course authoring systems are defined as edition environments that relieve the teacher of the programming work, in order to allow him to devote himself better to the pedagogical organization (Madaule, Passardière, Barril \& Calver, 1987). An authoring system can be defined as an "environment of high-level software development" (Nanard, 1996). This definition can be completed by that of Ackermann (1995): "An authoring system allows persons who don't know how to program, or who want to spare time in programming, or are not interested in programming, to create software." But these definitions seem vague. So, we are going to adopt a definition of the authoring system term with regard to the context of our work: "an authoring system is an environment, which has preprogrammed elements and allows users to create, modify and delete learning contents" (Murray et al., 1999). The main purpose is to allow the manipulation of the content by end users.

To encourage individuals who are skillful in diverse domains to use authoring systems, it is necessary to provide them with complete, simple, and useful tools that are used by actors having, in principle, no information and communication technologies skills. Several attributes that can affect any development method must be carefully studied and taken into account by courses designers (these attributes depend on the type and the level of the user of authoring system). The main criteria, according to $\mathrm{Wu}$ Yao Kurang (2000), are: user-friendliness, transparency, assistance, interactivity, and reliability.

\section{Related Works: Collaborative Authoring Systems}

During the last few years, several learning systems have been implemented and tailored to specific pedagogical approaches (Karampiperis \& Sampson, 2004). In fact, according to Karampiperis and Sampson (2004), several existing systems support the process of web-based authoring for providing active learning, constructive learning, collaborative learning, intentional learning, contextualized learning, reflective learning, etc. (Carr, 2001; Constantino-Gonzales, Suthers \& Escamilla de Los Santos, 2003; Jonassen \& Rohrer-Murphy, 1999; Marra \& Jonassen, 2001).

A number of collaborative authoring systems have been recently developed. The aim of these different systems varies: some are specifically supporting collaborative authoring, some are general 
purpose text editors, some support collaborative sketching or drawing, and some provide a framework for integrating existing editors into a collaborative environment (Zhai \& Wang, 2003).

In literature, several authoring systems were cited. The first system to cite here is MESSIE (Sasse, Handley \& Chuang, 1993). It is a collaborative authoring environment that supports the production of large-scale documents by teams of geographically distributed groups of authors working with heterogeneous systems. The environment allows authors to submit texts at various stages of gestation (e.g., list of topics, first draft) to a shared filestore via email. All authors collaborating on a document can read each others' contributions and add suggestions, comments, and additional material directly to the document (Sasse et al., 1993).

There are many systems that support collaborative editing of documents and hypermedias. GROVE (Ellis, Gibbs \& Rein, 1991) is one among these systems. It is a text editor designed to be used by a group of people simultaneously editing an outline document (tree-structured document that may be viewed at various levels of specificity) during a work session. Another system from this category is SASSE (Synchronous Asynchronous Structured Shared Editor) (Baecker, Glass, Mitchell \& Posner, 1994; Baecker, Nastos, Posner \& Mawby, 1993), which is an interactive synchronous writing tool. Also, SASSE supports asynchronous editing. Moreover, an annotation mechanism is provided to allow authors to exchange notes and comments.

One of the tasks that requires collaboration among teachers is collaborative writing. According to Cerratto and Rodriguez (2002), a fair amount of research has been conducted into the ways groups write together (Kim \& Eklundh, 2001; Posner, 1991; Zammuner, 1995). Much of these works agree on the idea that collaborative writing involves phases of writing and communication, periods of synchronous activity where the group works together at the same time, and periods of working alone where group members work at different times. Collaborative writing is a very complex and specific collaborative activity that differs from others in that written language is both the group's product and a means for communication between the writers (Cerratto \& Rodriguez, 2002).

Another work that studied the impact of collaborative writing in the higher education field is presented in Kasemvilas and Olfman (2009). The authors propose to use MediaWiki (one of the most popular wiki engines) in a classroom-based collaborative writing project. According to the authors, MediaWiki is a useful tool for supporting group collaboration.

Shared editors, as well as Calliope (Mitchell, 1996) and ZWikiCoop (Courtin \& Giraud, 2002), are among tools used to support the collaboration. Calliope is a shared editor that provides a main shared text workspace and a number of tools to raise collaborator awareness. Apart from this, Pinheiro, Telecken, Zeve, Valdeni de Lima \& Edelweiss (2001) have developed a cooperative environment for e-learning authoring that allows the cooperation between educators and technical people in order to create material for e-learning courses. The core of their approach was to use mainly web standards, like XML (eXtensible Markup Language), SMIL (Synchronized Multimedia Integration Language), SVG (Scalable Vector Graphics), and WebDAV (Web-based Distributed Authoring and Versioning), and open software. Furthermore, Perry (2002) developed a shared editing tool with messaging systems for scientific collaboration within a widely distributed environment.

Some researchers used other concepts and technologies for developing collaborative authoring systems. For instance, Dicheva, Aroyo. and Cristea (2002) had used the system AIMS (Agentbased Information Management System), and they introduced ontology-oriented support for collaborative courseware authoring. Furthermore, Virvou and Moundridou (2000) developed a webbased authoring tool for Intelligent Tutoring Systems. The tool aims to be useful to teachers and students of the domains that make use of algebraic equations. Qu, Gamper. and Nejdl (2001) developed a collaborative authoring system. They adopted a recent collaboration-friendly Internet 
protocol, WebDAV, to support collaborative courseware authoring, the markup-language XML to represent metadata of course contents, and the stylesheet language XSLT (Extensible Stylesheet Language Transformation) to accomplish courseware presentation.

Finally, Sung \& Lee (2004) developed a Collaborative Multimedia Authoring System. This system allows a group of users working at different machines to work on the same multimedia presentation and to communicate in real time. In any collaborative computing environment, multiple users or processes can access a shared object concurrently. In this situation, an inconsistency of shared data might occur and therefore a concurrency control is required.

A common criticism of most of the developed systems is that they consider only the vision of a single teacher and neglect the confrontation of several points of view on the same subject (i.e., collaboration among various teachers). Besides, they are not specially conceived to be used in higher education organizations and they do not take care of LMD (Licence-Master-Doctorate) regime (syllabus of subject to be studied, learning unit, credit, etc.). Furthermore, the feature of co-authors searching is absent in all the systems cited previously.

\section{Presentation of the System}

\section{Objectives of the System}

SAC is a system whose main purpose is to support learning activities of learners and the collaboration of teachers for the design of courses. It can be used by any academic institution (university, high school, etc.) adopting the LMD regime where the subjects are characterized by some information, such as teaching unit, syllabus, or credit.

Through this system:

- Teachers can collaborate for conceiving courses in various formats (tutorials, presentations, etc.).

- Students can download lessons, self-assess, communicate with teammates, and request assistance from their teachers.

In our system, teachers collaborate to realize a common product (the subject to be studied) and learners collaborate to learn together. Among the global objectives of the system, we can cite the following.

\section{Individualization of learning process}

SAC must insure the individualization of learning (each learner has his or her own space). It allows learners to view their subjects in an autonomous way, to estimate their knowledge, and to collaborate with their teammates by using the various available communication tools. Furthermore, it can keep the activities traces of each learner. All the learners held a space for saving their documents, notes and courses files. Many tools are provided to facilitate these functionalities.

\section{Collaborative authoring and co-authors searching}

For facilitating the collaboration between teachers or courses designers, SAC offers a co-authors search tool adopting several criteria (teacher's behavioral profile, teacher's degree, etc.). It allows teachers to collaborate with any one who satisfies some criteria according to their specifications. In addition, the system offers a collaboration space for the design of courses. It provides for each teacher an authoring space for creating the subjects easily and updating them, importing any type of files and attaching them to any concept of the subject and creating assessment exercises. 


\section{Architecture of the System}

As shown in Figure 1, our system is composed of three main interfaces (administrator, teacher, and learner). It possesses a Web server and a database containing various information about the actors of the system and their activities (subjects, interactions, etc.). We present in the following sections the available features in each human interface.

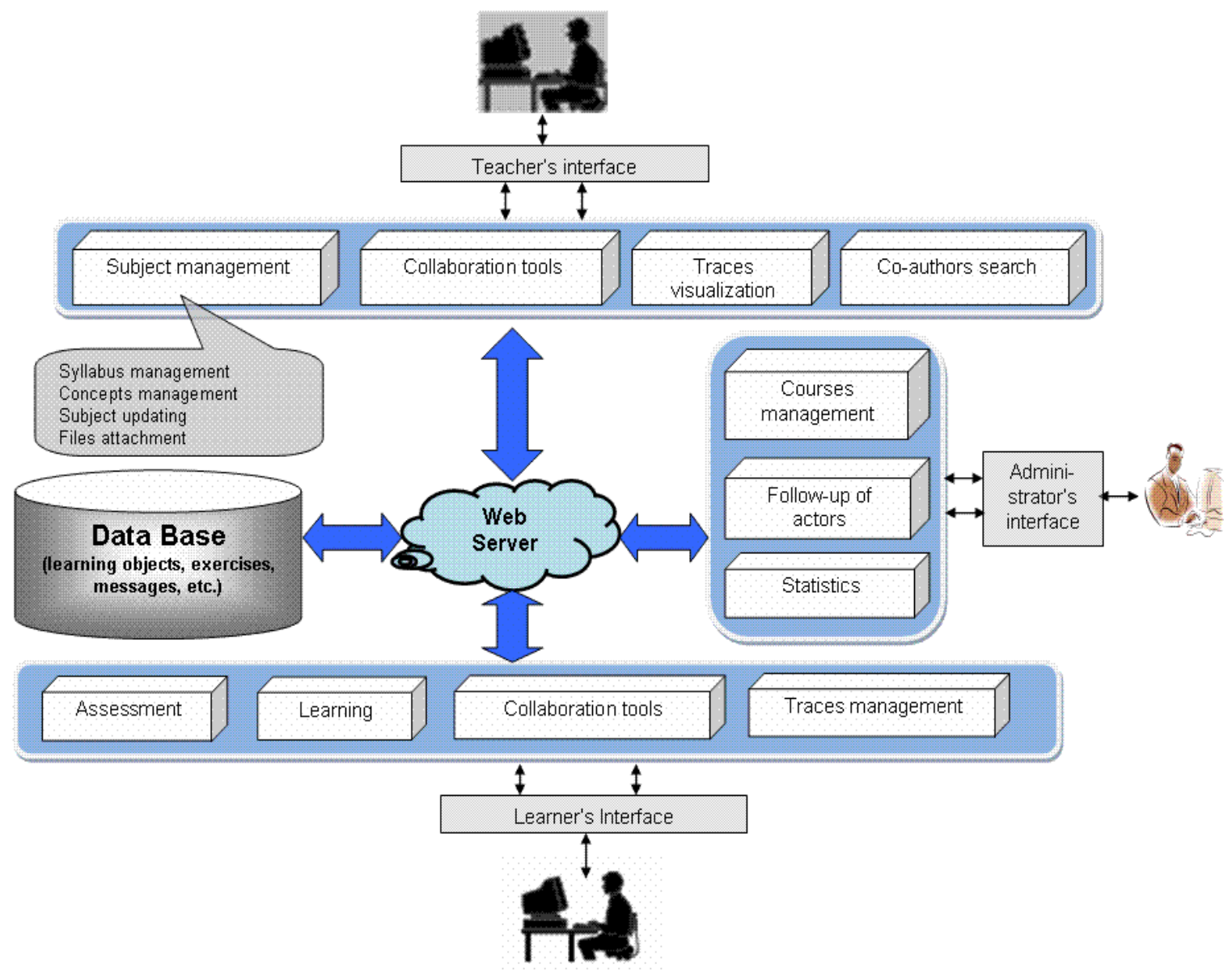

Figure 1: Architecture of the system.

\section{Teacher's interface}

The interface of the teacher contains the main functionalities of the system, which provides the teacher with a set of features that allow him to carry out his tasks in an effective way. Several tasks can be done by the teachers. We present the important ones in the following sub-sections.

\section{Syllabus preparation}

A syllabus is a set of information concerning the subject. It can be prepared by the teachers who can add the necessary information by collaborating. The required information is the following:

- Description of the subject.

- Pedagogical Objectives (PO) of the subject.

- Bibliographical references.

- Assessment modes. 


\section{Organization of the subjects.}

A subject is a structured set of pedagogical objectives (PO) that contain a set of concepts. In pedagogy, an objective is a statement of intention describing what the learner will know after the learning process. The pedagogical objectives are derived from education goals and training purposes. They are decomposed into intermediate objectives of various levels. In other words, a pedagogical objective is a coherent entity of knowledge that collects several pedagogical concepts. In our system, a pedagogical objective is defined by a title and a list of concepts that constitute the smallest entity in the architecture of the subject.

The teachers can introduce the concepts contents thanks to a shared text editor integrated in the subject management space. Furthermore, they can attach any type of file or any learning object (document, video sequence, PDF, presentation, etc.) and associate it with a pedagogical objective (Figure 2).

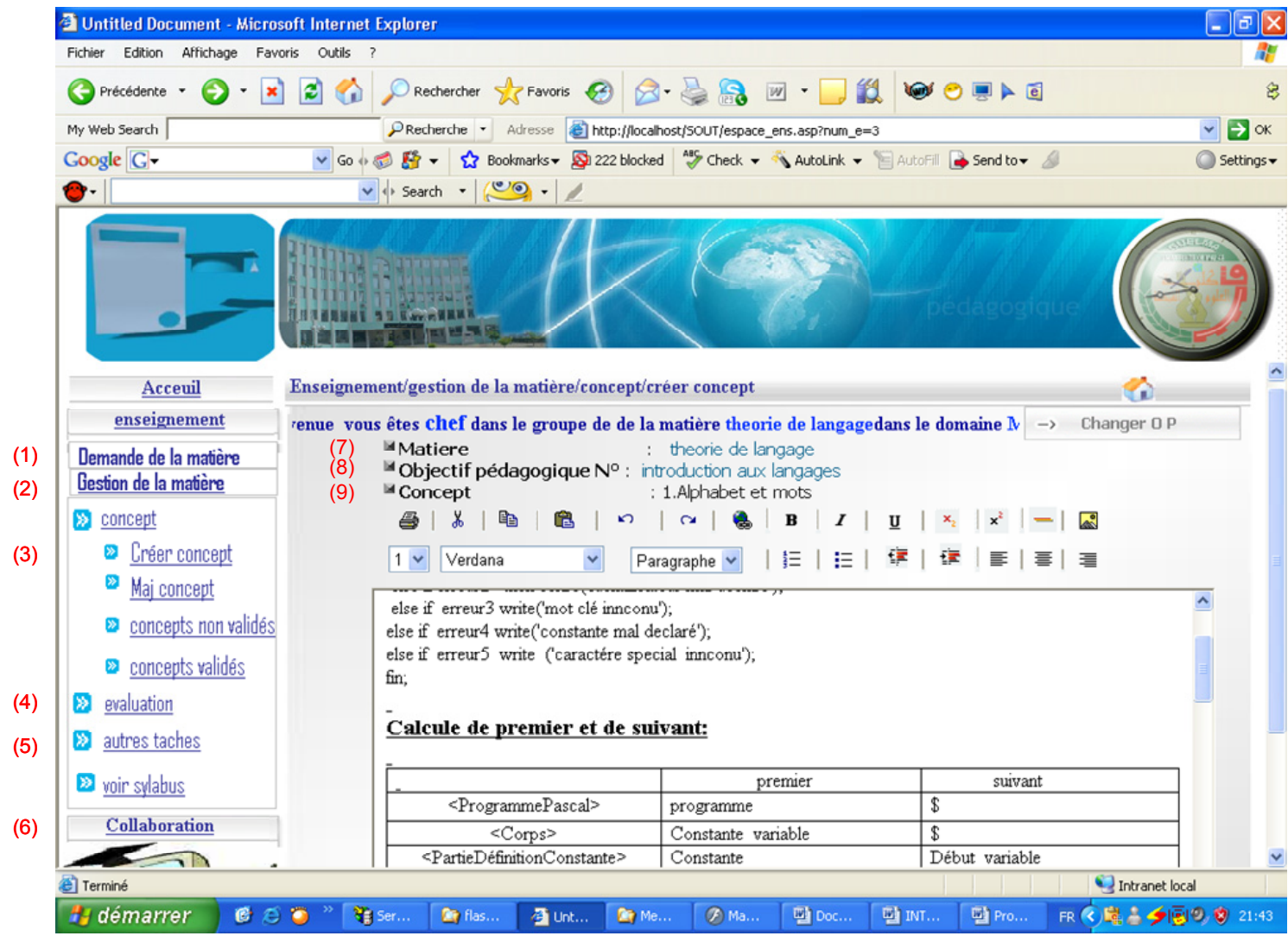

(1) Subject demand

(2) Subject management

(3) Concept management (Creation, Updating ...)

(4) Assessment (creation and update of assessment exercises)

(5) Syllabus visualization
(6) Collaboration

(7) Subject name

(8) Pedagogical objective name

(9) Concept name

Figure 2: Creation of concepts and pedagogical objectives in SAC.

\section{Creation of assessment exercises.}

Different types of exercises (multiple choice questions, true/false, etc.) were proposed in our system. The teacher proposes some exercises for each pedagogical objective. Each exercise contains a description, proposed answers, and correct answers. The answers of these questions can be used to calculate the cognitive profile of each learner. For each subject, the teachers can view some of 
Impact of Collaboration among Teachers

its indicators. Among these indicators we can cite the rate of success/failure, the frequency of downloading files, the duration of the assessment process, the average mark obtained for each subject, the number of students having problems in each subject, etc.

\section{Collaboration with other teachers.}

Teachers can collaborate with their teammates in order to build and edit together the subject contents or any other pedagogical resource. Teachers are organized in groups of small sizes (each group is composed of four members at most). The tools used to facilitate this task are chat for synchronous virtual meetings and forum and electronic mailing for asynchronous exchange. Besides, in turn a particular teacher is indicated as responsible person of the final version of the courses contents.

The teacher responsible for a subject needs to communicate with the other teachers concerned with the construction of the same subject. To insure this communication, the responsible teacher can organize synchronous meetings allowing the assembling of all concerned teachers.

\section{Search for co-authors.}

A very important aspect of a typical corporate educational environment is that there is not always an author available for development of courseware (Helic, Maurer, \& Scerbakov, 2002). For instance, an organization may have a technically skilled author responsible for the development of training objects, but he does not have enough knowledge on a particular subject to produce training objects of a reasonable quality. However, such an organization might have a number of experts in that particular subject who obviously have enough knowledge on that topic but they are probably not technically skilled to develop courseware (Helic et al., 2002). So, the feature of searching co-authors is very interesting. But, as it is indicated previously in this paper, there is no authoring system that provides this feature.

In our research, we have taken into account the co-authors search feature. In fact, to facilitate the collaboration between the teachers, a search engine of co-authors is available. It uses a set of search criteria: behavioral profile, expertise area, and authors' degrees. This search tool holds two search types: simple (by using keywords) and advanced (by using logical connectors: "and" and "or").

We describe in the following the criteria used by the co-author search tool.

a. Behavioral profile: it is associated with each teacher. It can have a set of values such as super collaborator, collaborator, isolated, etc. The behavioral profile is calculated from all the interactions established between the concerned teacher and the other teachers of the system. There is no standard formula to calculate this profile. In our system, behavioral profile represents the rate of participation of the teacher in each available communication tool.

b. Expertise area: it indicates the expertise field of each teacher. We have adopted the areas available at Algerian Universities with the possibility to extend this list by the administrator.

c. Degree (Rank/Level): the teachers of SAC have various degrees (professor, senior lecturer, assistant professor, etc.). Updating this information can be done by the teacher or the administrator of the system. 


\section{Learner's interface}

The main role of this interface is to offer to the learner access to training courses as well as communication and interaction spaces. We present, in this section, a description of the main activities provided by this interface.

\section{Learning Activity.}

Learners have a space to view the contents of subjects, assess their knowledge, and collaborate with their teammates. Figure 3 presents the content of a concept of "language theories" subject dedicated to students of $2^{\text {nd }}$ year (Licence degree of "computer science" specialty).

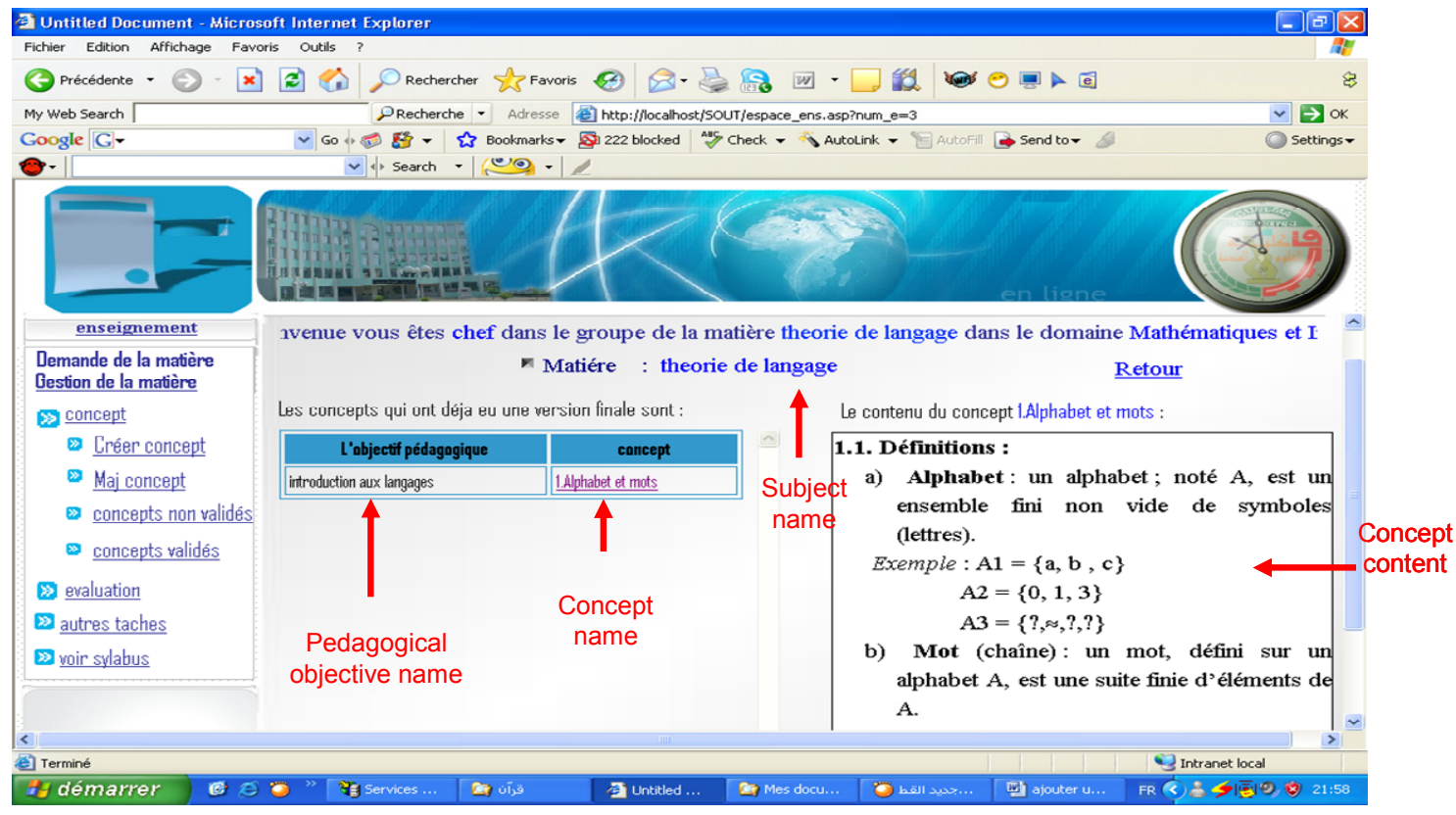

Figure 3: Contents of a concept of a learning subject.

\section{a. Navigation in the contents of subjects}

The learner can view the pedagogical objectives that their prerequisite pedagogical objectives are verified. Inside the subject, the learner follows the law of the prerequisite between the Pedagogical Objectives (PO). He cannot view any pedagogical objective if he did not acquire all its prerequisite pedagogical objectives. For example, if a pedagogical objective (X) has two prerequisite pedagogical objective $\mathrm{Y}$ and $\mathrm{Z}$, then the learner must acquired $\mathrm{Y}$ and $\mathrm{Z}$ before learning $\mathrm{X}$.

A set of tools is provided to keep his traces and the historic of all his actions. Furthermore, he can download the learning resources and save them into his personal repository (Figure 4).

\section{b. Annotation of subject contents}

During the learning process, the learner can write comments on the contents of any subject. These comments constitute a source of information for the teachers responsible for the subject. It is one of the actions offered to learners allowing the personalization of learning. These comments are stored in the data-base for a future use. Moreover, they can be ordered by date or viewing rates. 


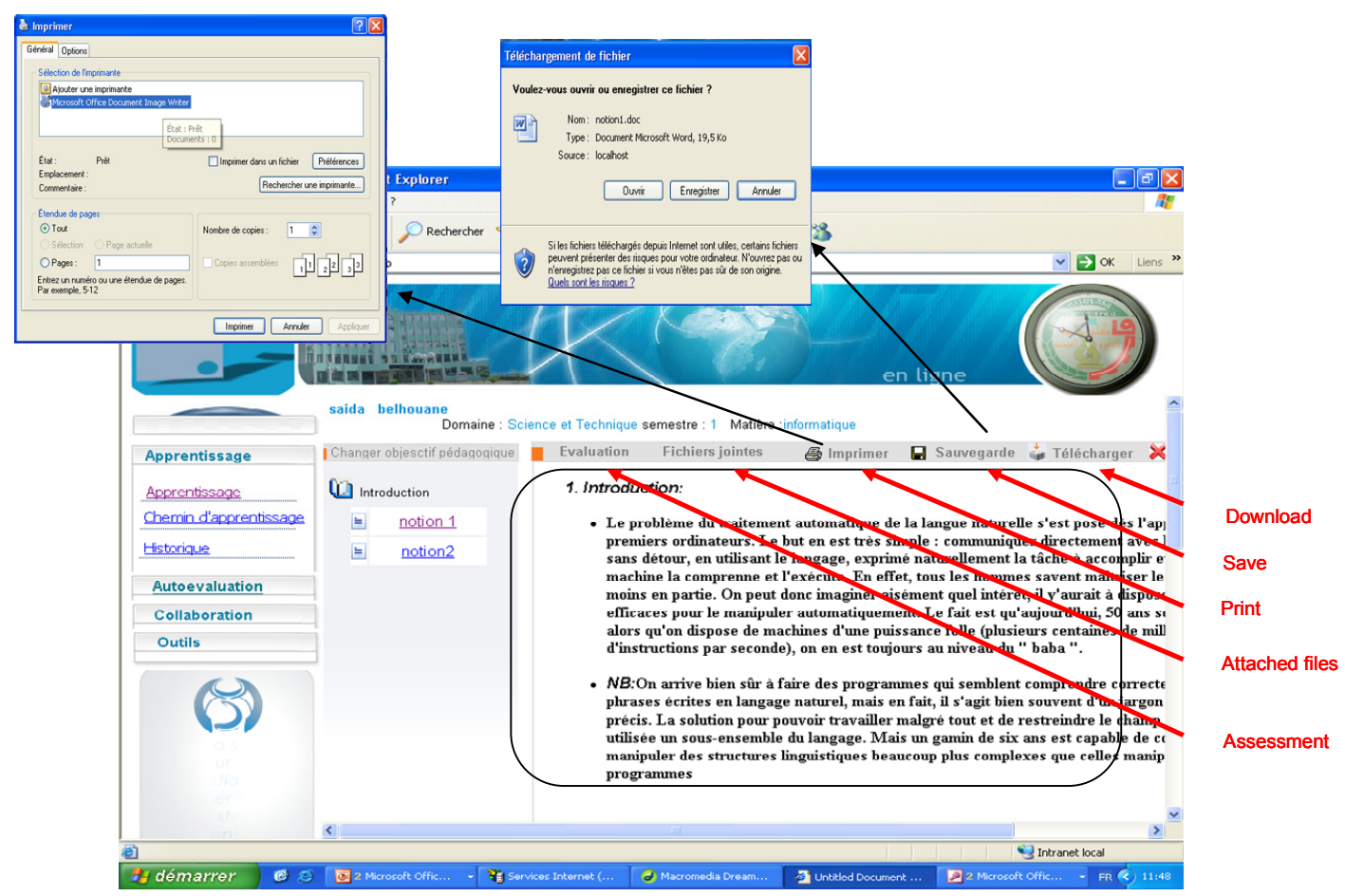

Figure 4: Download of attached files.

\section{Assessment Activity.}

Assessment is an essential stage in any learning process. The assessment process is done at the Pedagogical Objective (PO) level, so the learner can test his knowledge after visiting the concepts of a pedagogical objective. A PO is acquired if the learner obtains $50 \%$ of right answers. The teachers can view the obtained results for each learner following their subjects. These results can help teachers to extract the problems faced by learners, the quality of proposed exercises, etc.

\section{Traces visualization of realized pedagogical activities.}

During the learning session, the results of the learner's activities are safeguarded and constitute the history. In other words, all the actions done by the learners are saved. Also, they can be visualized under different formats. In a previous published paper, we have used some types of traces according to the pedagogical activity of the learners: assessment, learning, collaboration, etc. (Lafifi, Halimi, Ghodbani \& Salhi, 2009).

At any time, all the traces can be viewed by the learner. Among this information, we can mention:

- List of visited subjects,

- List of visited pedagogical objectives,

- List of visited concepts,

- List of solved exercises,

- List of unsolved exercises,

- Answers proposed for each solved exercise,

- List of collaborators, and

- Detailed list of messages sent and received for each communication activity.

A master work (at computer science department of Guelma University) is in progress permitting collecting, analyzing, and interpreting the traces of the activities performed by the learners. 


\section{Experiment}

In this section, we will present a description of an experiment that was conducted at the University of Guelma. First of all, we will begin by giving an overview of the subject to be studied and the participants. Then, we present the adopted methodology. At the end of the experiment, a questionnaire was submitted to the participants. The findings are presented and discussed in the next section. In addition, we will present some points of view of the participants (i.e., teachers and students) extracted from the questionnaire. Finally, we will present some problems faced by both teachers and learners.

\section{Overview}

An experimental study was conducted within Guelma University (Algeria) with $1^{\text {st }}$ year Licence students where the subject was "algorithmic". This subject is studied by several students in the Licence degree. In fact, students from MI (Mathematics and Informatics), ST (Science and Technology), Economics and Sciences of the Nature follow a subject of "initiation into informatics and algorithmic".

Students can use the system from any computer connected to the intranet of the university. We took in this experiment only students from the MI (Mathematics and Informatics) speciality. The subject constituted about one hundred concepts. A set of exercises was associated with each concept of the subject. These concepts and exercises were established by the collaboration of some teachers.

\section{Methodology}

This experiment allowed testing the view of the teachers during the collaboration between them to design the contents of the subject, on one hand, and the impact of this collective construction on learners' cognitive level, on the other hand. For that we divided the students $(n=59)$ into two groups that followed the same subject. The first group (control) $(n=29)$ followed the concepts of the subject in the form of an HTML file prepared by one of the teachers (the course was printed and distributed to students). The second group (experimental) $(n=30)$ used the system and followed a subject conceived by the collaboration of several teachers. With the cooperation of the administrative staff, we were able to reserve free sessions during all week days $(3 \mathrm{H} /$ day on average) for all the students concerned with this experiment. During the period of free sessions, the students could use any computer connected to the intranet of the University.

After three months of use, an examination was sent to all the learners (control and experimental groups). This examination was conceived by some of the teachers and contained several types of exercises marked on 20 points (as in the case of the evaluation in Algerian higher education organizations).

To extract problems encountered as well as the global opinion of the teachers and the students, we prepared one questionnaire to teachers and another one to students after using the system. The questions of the questionnaire are divided into three categories:

1. General opinion about the interface of the system and the main available features.

2. The quality of the interface of the concerned actor as well as its options.

3. The quality of the content of courses.

The objective of all the questions is to show the attitude and the opinion of each actor about the main interface of the system and its utility, the special features provided to each actor, and finally to know the impact of the collaboration among teachers on the content of learning objects, the skills of teachers, and the knowledge level of learners. 


\section{Results and Discussion}

We drew several conclusions after three months of system use. Firstly, students and teachers have appreciated the use of the system. Secondly, the majority of students appreciated the contents of the subject (object of the experiment). Thirdly, the teachers were very satisfied with the proposed authoring tool as well as the co-authors search tool. They appreciated the collaboration between them for the construction of subjects. Fourthly, the results of the exam demonstrated that the obtained marks of the experimental group students were better than those of the control group students.

Generally speaking, according to the obtained results some questions asked previously (in the introduction of this paper) can be resolved. Firstly, the collaboration among teachers has positive effects on the cognitive profiles of learners and on the teachers' skills, such as the discussion, the argumentation, and the pedagogical organization of courses. Secondly, the results showed that the proposed tools were sufficient for doing the teachers' tasks. In fact, most of teachers used the shared text editor and the co-authors search engine. We give in the following sections, the evaluation of both teachers and learners and the problems faced.

\section{Views of Teachers}

The questionnaire submitted to teachers is composed of 15 questions (see the Appendix). Only twenty teachers of various departments answered all the questions of the questionnaire. Generally speaking, all the teachers were satisfied with the tools provided for the online edition of their courses as well as the collaboration tools provided by SAC. Concerning the collaboration between teachers, we noticed that all teachers exchanged conversations with their pairs. $75 \%$ of them appreciated the results of such collaborations and the nature of the exchanges.

Concerning a question about the time to complete the subject contents, $50 \%$ of teachers considered that the time is acceptable, whereas $40 \%$ estimated the time was too long and $10 \%$ did not give their opinion.

We cite the points of view of two teachers about the system (they are translated from French).

Teacher 1: It is the first time in my life to use an online system for preparing my courses. I think that is a good system with many features. I well appreciated the shared text editor where a lot of options are provided for good organizing the courses. Also, I appreciated collaboration with other colleagues, but the impatience of some of them of the delay of preparing courses was a serious problem. I suggest to use means for keeping the previous activities of colleagues and to ameliorate the space for creating exercises. Furthermore, I propose to add other types of exercises. For instance, in my subject, I need other types of exercises like filling in the gaps.

Teacher 2: This system has a good interface and many good features. The means provided for preparing our courses are good but they are insufficient. I propose to add more tools and means. In addition, I want to obtain more information about the difficulties met by my students when teaching my subjects. The collaboration tools are good, but I suggest saving all the interactions done in chat session and why not using Videoconferencing mode.

We present in what follows (Table 1) some responses of the teachers about the main questions of the questionnaire. 
Table 1: Responses of teachers after the experiment.

\begin{tabular}{|c|c|c|c|c|}
\hline Question & \multicolumn{4}{|c|}{ Answers } \\
\hline \multirow{2}{*}{$\begin{array}{l}\text { Do you think that the use of } \\
\text { this system is }\end{array}$} & Very easy & Easy & Difficult & Very difficult \\
\hline & $1(5 \%)$ & $14(70 \%)$ & $5(25 \%)$ & $0(0 \%)$ \\
\hline \multirow{2}{*}{$\begin{array}{l}\text { Are you satisfied with the } \\
\text { teacher space? }\end{array}$} & Yes & Slightly & \multicolumn{2}{|c|}{ No } \\
\hline & $15(75 \%)$ & $5(25 \%)$ & \multicolumn{2}{|c|}{$0(0 \%)$} \\
\hline \multirow{2}{*}{$\begin{array}{l}\text { How do you find the shared } \\
\text { text editor interface? }\end{array}$} & Very good & Good & Average & Weak \\
\hline & $1(5 \%)$ & $13(65 \%)$ & $5(25 \%)$ & $1(5 \%)$ \\
\hline \multirow{2}{*}{$\begin{array}{l}\text { How do you find the co- } \\
\text { authors search tool? }\end{array}$} & Very efficient & Efficient & $\begin{array}{c}\text { Quite } \\
\text { Efficient }\end{array}$ & Not efficient \\
\hline & $14(70 \%)$ & $6(30 \%)$ & $0(0 \%)$ & $0(0 \%)$ \\
\hline $\begin{array}{l}\text { How do you see collaboration } \\
\text { with other teachers? }\end{array}$ & $2(10 \%)$ & $15(75 \%)$ & $3(15 \%)$ & $0(0 \%)$ \\
\hline \multirow{2}{*}{$\begin{array}{l}\text { Does collaboration help you } \\
\text { to improve your knowledge? }\end{array}$} & Yes & Slightly & & No \\
\hline & $18(90 \%)$ & $2(10 \%)$ & \multicolumn{2}{|c|}{$0(0 \%)$} \\
\hline \multirow{6}{*}{$\begin{array}{l}\text { What do you think about team } \\
\text { working? }\end{array}$} & \multicolumn{4}{|c|}{ Effectiveness } \\
\hline & Very efficient & Efficient & Quite efficient & Not efficient \\
\hline & $5(25 \%)$ & $14(70 \%)$ & $1(5 \%)$ & $0(0 \%)$ \\
\hline & \multicolumn{4}{|c|}{ Motivation } \\
\hline & $\begin{array}{c}\text { Very } \\
\text { motivating }\end{array}$ & Motivating & $\begin{array}{c}\text { Quite } \\
\text { motivating }\end{array}$ & Not motivating \\
\hline & $2(10 \%)$ & $17(85 \%)$ & $1(5 \%)$ & $0(0 \%)$ \\
\hline
\end{tabular}

From Table 1, we can extract some results. First of all, some teachers found some difficulties when using the system. One of the difficulties is the cognitive overloading. In reality, theses teachers found a lot of options in the same page (i.e., overloaded pages). One teacher had noticed the existence of unnecessary fields in some interfaces of the system.

Among our main contributions in this research work is the co-authors search engine. We noticed that the teachers were very satisfied about this tool and its features. Furthermore, the teachers found that the available search types are very sufficient and the used criteria are also very efficient. Although this study was conducted on a small sample, we can say that the criteria used reflect the needs of most teachers.

By analyzing co-authors searching queries, we found that the most used criterion is "expertise area," and "simple type" is the most used search type.

Another goal of this experiment is to know to what extent teachers are able to collaborate with their teammates. As it is represented by Table 1, the teachers noticed that the collaboration is very efficient for designing their lessons. Moreover, they were very motivated to work together in order to consolidate their knowledge and their skills. One teacher said, "The collaboration is very efficient because I profit from the experience of other colleagues." Another teacher said, "I prefer to work with other colleagues to save time."

The main difficulty mentioned by the teachers is the lack of a tool for saving traces of conversations made between them. Most of teachers said that they would like a tool for saving the conversations. 
Concerning the pedagogical content quality, some teachers mentioned the problem of inserting video sequences and multimedia files. In fact, our system let teachers to insert any file but without the supporting device (e.g., device for reading wave and/or video files). In addition, some teachers indicated the problem of respecting the time taken for courses preparation by other colleagues of the same group.

Finally, an important remark concerns the contents of the sent messages. They are written in several languages (Arabic, French, Arabic-French mixture) and contain many spelling mistakes. Some teachers indicated the problem of the misunderstanding many of the messages sent by certain students.

\section{Views of Learners}

To determine the views of learners who participated in this experiment (constituting the experimental group), we submitted to them a questionnaire, which is composed of 25 questions (see the Appendix). These questions concern three pedagogical activities: learning, assessment, and collaboration. A particular interest was attributed to the contents of training subjects that are collaboratively conceived.

First of all, $80 \%$ of students judged that training contents are well edited. Furthermore, they appreciated the service of downloading courses (learning objects), exercises, and other available resources. All available collaboration tools were used with different cadences. The majority of learners prefer the chat $(60 \%), 30 \%$ of them prefer the forum, and $10 \%$ of them prefer the electronic mailing. A research study is in progress in the computer science department (Guelma University) to study the reasons of such choices as well as the analysis of interaction contents.

Here are the points of view of two students about the system (they are translated from French).

Student 1: It is a good system, which lets me learn at distance from anywhere. I appreciate the contents of subjects and the communication tools. There are problems with the quality of assessment exercises and the refusal of some good learners to collaborate with me.

Student 2: Generally speaking, I find that this system is good. There are many good features such as downloading courses, collaborate with colleagues of class, communication with my teachers, etc. But, it has some problems with the interface, which contains many additional options. I suggest to minimize the option list, and to take into account the use of colors and the animation to attract the other students.

Table 2 presents some of the responses of the experimental group students (30 students). 
Table 2: Responses of learners after the experiment.

\begin{tabular}{|l|c|c|c|c|}
\hline \multirow{2}{*}{ Question } & \multicolumn{4}{c|}{ Answers } \\
\hline \multirow{2}{*}{$\begin{array}{l}\text { Do you think that the use of } \\
\text { this system is }\end{array}$} & Very easy & Easy & Difficult & Very difficult \\
\cline { 2 - 5 } & $4(13.33 \%)$ & $24(80 \%)$ & $2(6.66 \%)$ & $0(0 \%)$ \\
\hline \multirow{2}{*}{$\begin{array}{l}\text { How do you see the } \\
\text { organization of the learning } \\
\text { objects? }\end{array}$} & Very good & Good & Average & Weak \\
\cline { 2 - 5 } & $3(10 \%)$ & $20(66.66 \%)$ & $6(20 \%)$ & $1(3.33 \%)$ \\
\hline $\begin{array}{l}\text { The content of learning } \\
\text { objects is }\end{array}$ & Very clear & Clear & Quite clear & Not clear \\
\cline { 2 - 5 } & $2(6.66 \%)$ & $24(80 \%)$ & $4(13.33 \%)$ & $0(0 \%)$ \\
\hline \multirow{2}{*}{$\begin{array}{l}\text { How do you see the } \\
\text { efficiency of the system? }\end{array}$} & Very efficient & Efficient & $\begin{array}{c}\text { Quite Effi- } \\
\text { cient }\end{array}$ & Not efficient \\
\cline { 2 - 5 } & $20(66.66 \%)$ & $8(26.66 \%)$ & $2(6.66 \%)$ & $0(0 \%)$ \\
\hline $\begin{array}{l}\text { How do you see the } \\
\text { assessment questions? }\end{array}$ & Very easy & Easy & Difficult & Very difficult \\
\cline { 2 - 5 } $\begin{array}{l}\text { Do you prefer the learning } \\
\text { objects done by a single } \\
\text { teachers or a group of } \\
\text { teachers? }\end{array}$ & Single teacher & $\begin{array}{c}\text { Group of } \\
\text { teachers }\end{array}$ & \multicolumn{2}{|c|}{ Both } \\
\cline { 2 - 6 } & $0(0 \%)$ & $28(93.33 \%)$ & \multicolumn{2}{|c}{$2(6.66 \%)$} \\
\hline
\end{tabular}

As far as students are concerned, we noted from Table 2 that the system was easy to use for most of them. According to them, the learning objects were organized in a good manner. Only one student said that this organization is weak. The learning objects were clear for the majority of students. One student said that "the content of the courses is very well organized; it contains all the necessary information." Another one said that "any lesson contains a lot of examples, figures and exercises." He added "I think that the content of lessons is very clear and easy to learn."

Last but not least, a very important point of this study is that the students prefer the lessons designed by the collaboration of a set of teachers. Indeed, $95 \%$ of them said that collaboration between teachers has a good effect on lesson quality. We remember that these learning objects were designed by teachers grouped into small groups (four teachers per group).

\section{Conclusions and Future Work}

The Web is fundamentally changing the way education is done. Today, not only in the so-called virtual universities but also in many traditional universities, more and more courses are partially or even entirely provided directly on and through the Web. Web-enabled global cooperation in education as well as web-enabled new pedagogical methods have provided us more possibilities to reduce the cost of education and to improve the efficiency and quality of the teaching and learning process, although at the same time they provide more challenges in Web-based courseware design (Qu et al., 2001).

A Web-based course does not only provide access to local documents but has also the function of a gateway, allowing access to educational materials or full courses elsewhere in the world. These features have a direct impact on the courseware authoring process. Authoring web courses means authoring environments, which are implicitly or explicitly open for sharing (Dicheva et al., 2002).

Many Web-based learning environments have been implemented by developers. Some of them support the collaborative authoring of subjects (or learning objects) that require the collaboration between teachers. This research belongs to this category. This paper has presented an authoring 
system, which is intended to be used as a collaborative learning platform in the higher education field. We have focused on features provided to teachers, since the first objective of this system is to provide the teachers with a variety of tools to structure the content of their subjects.

The system presented in this paper (SAC) facilitates the collaboration between the teachers. They can discuss the contents of a subject, pedagogical strategy to be adopted, means and contents of learners' knowledge evaluation, organization of concepts and pedagogical objectives, etc. The discussion and exchange of ideas among teachers of the same subject allows the confrontation of several pedagogical strategies. Thus we enable teachers to form groups (of small size) to manage the collaboration process better and guarantee that everybody participates in the subject preparation.

With the spread of the LMD (Licence-Master-Doctorate) regime in Algeria, we took into account the Licence degree. So, our system is useful for the university community. Our work is focused on teachers who are not specialized in ICT (Information and Communication Technology) and who possess only basic knowledge in ICT. At present, SAC is used only in French but we plan to take into account other languages.

As an answer to the questions cited in the introduction of this paper, we can say that collaboration among teachers as well as learners has good impact on the cognitive profiles of learners and increases the knowledge level of teachers. To facilitate the collaboration process, many tools are provided in SAC; for instance, a shared text editor can be used for preparing the subject matter or the assessment exercises. There are many researchers that used the principle of the shared text editor (Courtin \& Giraud, 2002; Ellis et al., 1991; Perry, 2002; Pinheiroet al., 2001). Another tool that can help to improve the collaboration among teachers is the co-authors search engine. This tool uses many criteria and has many important features. Furthermore, to our knowledge, there is no other system which uses the co-author search engine as ours does.

For answering the questions about the manner to determine the impact of the collaboration on the learners' knowledge and the opinion of the actors on the content of the obtained learning objects, we conducted an experiment during a period of three months at an Algerian University. Teachers and students of various departments can use the system from any computer connected to the intranet of the university. The first results of this experiment were very encouraging. Most of the teachers and the learners appreciated the use of the system. As a result, we drew several conclusions and several research tracks were opened.

As future work, we suggest the integration of Arabic and English languages for the preparation of the subjects. So, the aim is to provide teachers with an interface completely in Arabic or in English to facilitate the exploitation and the use of the system. As a result, we can take into account more subjects taught in these languages. Furthermore, we intend to provide more freedom to the teachers to form their own groups according to their needs; at present, the constitution of teachers' groups is randomly done.

\section{Acknowledgements}

We wish to thank the students and teachers of the University of Guelma who have participated in this experiment. We would also like to thank all those involved in course design, development and implementation of the system. Finally, a special thanks is addressed to Dr. Janice Whatley for her revision of the paper and her multiple comments. 


\section{References}

Ackermann, E. (1995). Environnements interactifs : Culture de zappeurs ou culture d'auteurs. Environnements Interactifs d'Apprentissage avec Ordinateur, 4èmes Journées EIAO-ENS de Cachan, Tome 2, Editions Eyrolles.

Baecker, R., Glass, G., Mitchell, A., \& Posner, I. (1994). SASSE: The collaborative editor [video tape transcript]. Conference Companion on Human Factors in Computing Systems (CHI'94), April, Massachusetts, USA.

Baecker, R-M., Nastos, D., Posner, I-R., \& Mawby, K-L. (1993). The user-centred iterative design of collaborative writing software. Proceedings of InterCHI'93, ACM Press: New York, 399-405.

Carr, C. (2001). Computer-supported collaborative argumentation: Supported problem-based learning in legal education. In P. Dillenbourg, A. Eurelings, \& K. Hakkarainen (Eds.), European perspectives on computer-supported collaborative learning (pp. 148-155). Maastricht McLuhan Institute.

Cerratto, T., \& Rodriguez, H. (2002). Studies of computer supported collaborative writing. Implications for system design. In M. Blay-Fornarino, A. Pinna-Dery, K. Schmidt, \& P. Zaraté, Cooperative systems design (pp. 139-154). Amsterdam: IOS Press.

Collis, B. (1999). Design, development and implementation of a WWW-based course-support system. ICCE99, Amsterdam: IOS Press, 11-18.

Constantino-Gonzalez, M-A., Suthers, D., \& Escamilla De Los Santos, J-G. (2003). Coaching web-based collaborative learning based on problem solution differences and participation. International Journal of Artificial Intelligence in Education, 13(2-4), 261-297.

Courtin, C., \& Giraud, S. (2002). A web collaborative editor: Awareness indicators in an experiment at school. IEEE Distributed Systems ONLINE, 4th Int. Workshop on Collaborative Editing systems ACM Conference on Computer Supported Cooperative Work, New Orleans, Louisiana, USA, November 2002 .

Cristea, A-I., \& Okamoto, T. (2001). Object-oriented collaborative course authoring environment supported by concept mapping in MyEnglishTeacher. Pedagogical Technology \& Society, 4(2).

Dicheva, D., Aroyo, L., \& Cristea, A. (2002). Collaborative courseware authoring support. CATE'02, ACTA Press, ISBN: 0-88986-332-6, 52-57.

Ellis, C-A., Gibbs, S-J., \& Rein, G-L. (1991). Groupware: Some issues and experiences. Communications of the ACM, 34(1), 38-58.

Helic, D., Maurer, H., \& Scerbakov, N. (2002). Aspects of collaborative authoring in WBT systems. Proceedings of the International Conference in Infrastructure for Electronic Business, Education, Science, and Medicine on the Internet [CD-ROM Publication], ISBN 88-85280-62-5, SSGRR 2002w, paper 37, SSGRR, LAquila, Italy.

Jonassen, D-H., \& Rohrer-Murphy, L. (1999). Activity theory as a framework for designing constructivist learning environment. Educational Technology Research and Development, 47(1), 61-79.

Kaplan, H. (1998). Building your own web course: The case for off-the-shelf component software. CAUSE/EFFECT, 21(4). Retrieved from: http://www.educause.edu/ir/library/html/cem9849.html

Karampiperis, P., \& Sampson, D. (2004). A flexible authoring tool supporting adaptive learning activities. Proceedings of IADIS International Conference on Cognition and Exploratory Learning in Digital Age (CELDA 2004), ISBN: 9729894779, Lisbon, Portugal, IADIS Press, 51-58.

Kasemvilas, S., \& Olfman, L. (2009). Design alternatives for a MediaWiki to support collaborative writing in higher education classes. Issues in Informing Science and Information Technology, 6, 45-64. Retrieved from http://iisit.org/Vol6/IISITv6p045-064Kasemvilas648.pdf

Kim, H-C., \& Eklundh, K. S. (2001). Reviewing practices in collaborative writing. Computer Supported Cooperative Work: The Journal of Collaborative Computing, 10(2), 247-259. 
Labidi, S., Lima, C-M., \& Sousa, C-M. (2000). Modeling agents and their interaction within SHIECC: A computer supported cooperative learning framework. Revue D'information Scientifique Et Technique, $10(1), 41-54$.

Lafifi, Y. (2007). SACA: un système d'apprentissage collaboratif. PhD thesis, Computer science department, University of Annaba, Algeria.

Lafifi, Y. (2008). SAC: Un système auteur collaboratif. Colloque CEMAFORAD 4, Strasbourg, France, April 2008. Available online at: http://edison.u-strasbg.fr/openconf/papers/66.doc

Lafifi, Y., Halimi, K., Ghodbani, A., \& Salhi, N. (2009). Learners monitoring based on traces in CSCL system. INFOCOMP: Journal of Computer Science, 8(2), 61-72.

Lonchamp, J. (2006). Supporting synchronous collaborative learning: A generic, multi-dimensional model. International Journal of Computer Supported Collaborative Learning, 1(2), 247-276.

Madaule, F., Passardière, B., Barril, P., \& Calver, F. (1987). Système d'enseignement assisté par ordinateur. Technique et science informatique, 6.

Marra, R., \& Jonassen, D-H. (2001). Limitations of online courses for supporting constructiviste learning. Quarterly Review of Distance Education, 2(4), 303-317.

Mitchell, A. (1996). Communication and shared understanding in collaborative writing. MS Thesis, University of Toronto, Department of Computer Science.

Murray, T., Condit, C., Piemonte, J., Shen, T., Khan, S., \& MetaLinks, A. (1999). Framework and authoring tool for adaptive hypermedia. Proceedings of AIED-99, 9th International Conference on Artificial Intelligence in Education, Le Mans, France, 744-746.

Nanard, M. (1996). Le multimédia, de l'âge artisanal à l'âge industriel. Rapport, LIRMM, Montpellier, France.

Perry, M. (2002). Use scenarios for shared editing in scientific collaborations. Proceedings of the Fourth International Workshop on Collaborative Editing Systems Hosted by the ACM Conference on Computer Supported Cooperative Work, New Orleans, Louisiana, November 16.

Pinheiro, M-K, Telecken, T., Zeve, C., Valdeni de Lima, J., \& Edelweiss, N. (2001). A cooperative environment for e-learning authoring. Document Numérique, 5(3-4), 89-114.

Posner, I. (1991). A study of collaborative writing. M.S. Dissertation, University of Toronto, Canada.

Qu, C., Gamper, J., \& Nejdl, W. (2001). Collaborative courseware authoring and publishing based on WebDAV, XML and XSLT. Proceedings of the IEEE International Conference on Trends in Communications (IEEE EUROCON 2001), Bratislava, Slovak Republic, July 2001.

Roberts, T-S. (2005). Computer supported collaborative learning in higher education. Idea Group Publishing.

Sasse, M-A., Handley, M-J., \& Chuang, S-C. (1993). Support for collaborative authoring via email: The MESSIE environment. Proceedings of the Third European Conference on Computer-Supported Cooperative Work, 13-17 September, 1993, Milan, Italy. G. De Michelis, C. Simone and K. Schmidt (Editors).

Serce, F-C., \& Yildrim, S. (2006). A web-based synchronous collaborative review tool: Acase study of an on-line graduate course. Pedagogical Technology \& Society, 9(2).

Smith, R-O. (2005). Working with difference in online collaborative groups. Adult Education Quarterly, $55(3)$.

Soh, L-K., Khandaker, N., Liu, X., \& Jiang, H. (2006). A computer-supported cooperative learning system with multi-agent intelligence. AAMAS'06, Hakodate, Hokkaido, Japan.

Sung, M-Y., \& Lee, D-H. (2004). A collaborative multimedia authoring system. Grid and Cooperative Computing, Part II, LNCS (Lecture Notes in Computer Science) on The Second International Work- 
shop GCC 2003, Shanghai, China, 2003.12.7-10, Revised Papers, Part II, V3033/2004, 311-318, Springer-Verlag, April 2004.

Synnes, K., Parnes, P., Widen, J., \& Schefstroem, D. (1999). Net-based learning for the next millennium. SCI/ISAS99, Florida, USA, Retrieved from: http://www.cdt.luth.se/ unicorn/papers/sciisas99/sciisas99.pdf

Virvou, M., \& Moundridou, M. (2000). A web-based authoring tool for algebra-related intelligent tutoring systems. Educational Technology \& Society, 3(2).

Wu Yao Kurang, R. (2000). La robustesse des systèmes auteurs multimédias: Contribution théorique et mise en cuvre. $\mathrm{PhD}$ thesis, University of Paris, France.

Zafer, A-A. (2001). NetEdit: A collaborative editor. Master Thesis, Faculty of the Virginia, USA. Retrieved from: http://scholar.lib.vt.edu/theses/available/etd-05032001113750/unrestricted/FinalThesis.pdf

Zhai, J., \& Wang, L. (2003). Computer supported collaborative editing system with speech-recognition functionality. The Fifth International Workshop on Collaborative Editing CECSCW 2003, Helsinki, Finland.

Zammuner, V. (1995). Individual and cooperative computer-writing and revising. Who gets the best results? Learning and Instruction, 5, 101-124.

\section{Appendix}

\section{Questionnaire of the Teachers}

1. Are you satisfied with online teaching?

2. Do you think that the use of this system is: very easy, easy, difficult or very difficult?

3. How do you find the system interface?

4. How do you see the efficacy of the system?

5 . Are you satisfied with the teacher space?

6. How do you see the shared text editor interface?

7. How do you see collaboration with other teachers?

8 . How do you find the co-authors search tool?

9. In your opinion, what is the important type of search for finding the good collaborators?

10. In the advanced search type, the criteria used are: very sufficient, sufficient, quite sufficient or not sufficient?

11. After the search, how did you find the search results?

12. How do you see the time of the collaborative preparation of subjects?

13. What do you think about team working?

14. What do you think about collaboration tools (Forum, Chat and Mail)?

15. Does collaboration help you to improve your knowledge?

\section{Questionnaire of the Learners}

1. During the enrolment phase, did you find all the required fields?

2. Are you satisfied with the online learning?

3. Does the help system help you to understand well the functionalities of the system?

4. Do you think that the use of this system is: very easy, easy, difficult or very difficult?

5 . What do you think about the system?

6 . How do you see the efficacy of this system?

7. How do you find the system interface?

8. Are you satisfied with the student space?

9. How do you see the organization of the learning objects? 
10. Do you think that the display of learning objects according to your cognitive profile is useful for improving your learning?

11. What is your opinion on the collaboration request space?

12. What is the type of the assistance requests the most useful to you?

13. The content of learning objects is: very clear, clear, quite clear or not clear?

14. How do you see the assessment questions?

15. How do you see the number of assessment questions?

16. Do you prefer the learning objects done by a single teacher or a group of teachers?

17. All your activities will be stored as traces to be viewed by your teacher, how do you see the usefulness of these traces?

18. How do you see the quality of traces display?

19. How do you see the responses of your teacher?

20. What do you think about the team working?

21. What do you think about collaboration tools (Forum, Chat and Mail)?

22. Does the collaboration help you to improve your knowledge?

23. Does the learning space contain all the student's learning needs?

24 . What are the three strengths of the system?

25 . What are the three weaknesses of the system?

\section{Biographies}

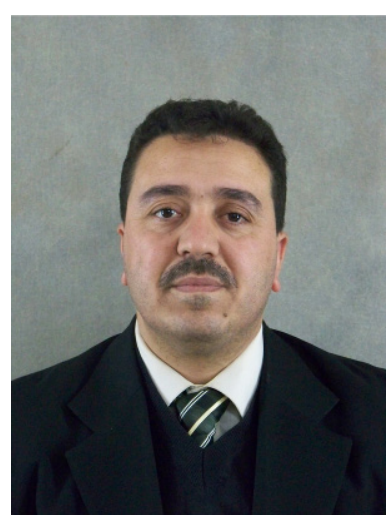

Dr. Yacine Lafifi received his Ph.D. in computer science from the University of Annaba (Algeria) in 2007. He also possesses the Magister degree in computer science from Annaba University in 2000. He is currently working as an Associate Professor at the Computer Science Department of Guelma University, Algeria. He has several published papers in various journals and international conferences. His current research interests are Collaborative learning, CSCL, e-Learning, Social networks and Virtual Communities.

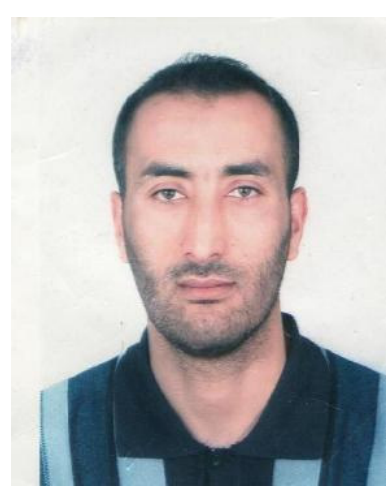

Ghassen Touil received his Magister degree in computer science from Boumerdes University (Algeria) in 2006. He also possesses the Engineer degree from Institut National d'Informatique (INI) in Algiers (Algeria) in 2001. Currently, he is an assistant teacher at the Computer science department of Guelma University, Algeria. His main research interests are focused on bioinformatics and E-learning. 